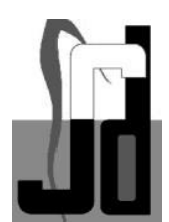

CASE REPORT

\title{
Congenital Lower Paramedian Lip Pits - A Rare Case Report
}

Prathima GS, Jayaraj D.

ABSTRACT: Lip pits are among the rarest congenital deformities recorded. Initially reported in 1845, its familial occurrence has been repofted just once. These developmental anomalies occur either as an isolated defect or in association with other developmental deformities including cleft lip, cleft palate or both. It may be located at the commissures of the lips or in the midline of the lower lip. It is often inherited as an autosomal dominant trait with variable penetrance. We report a case ofcongenital lip pit manifesting in the lower lip in a 12 year old male child.

Key words: Congenital, Lip Pits, Paramedian.

Paramedian lip pits are rare congenital invaginations Of the lower lip. They are believed to arise from persistent lateral sulci on the embryonic mandibular arch. Paramedian lip pits typically appear as bilateral and symmetric fistulas on either side of the midline of the vermillion of the lower lip. The present case report describes a 12 year old male child who presented with congenital lower paramedian lip pits.

\section{CASE REPORT}

A 12-year-old male child reported for treatment of a deformity of his lower lip. The lower lip deformity (FigI) represented two paramedian, invaginated, soft, painless, nonsecreting lesions. The symptoms were unchanged throughout the child's life, but the family was concerned about his aesthesis. The rest of the patient's medical history was non-contributory. The patient's family history was negative for the presence oflip pits.

On examination, the patient was found to have a submucosal cleft (Fig-2,3). The remainder of the patient's social, birth, and medical history were unremarkable. Results of his cardiovascular and genitourinary evaluations were normal.

\section{DISCUSSION}

Congenital lip pits are among the rarest congenital deformities recorded. [ ${ }^{11}$ The first report was described in

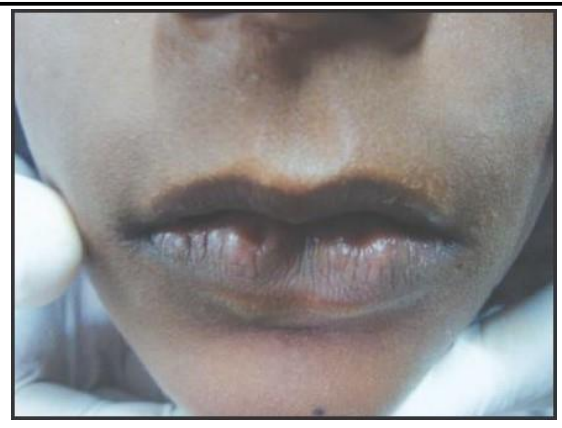

Fig 1:Bilateral Paramedian Lower Lip Pit

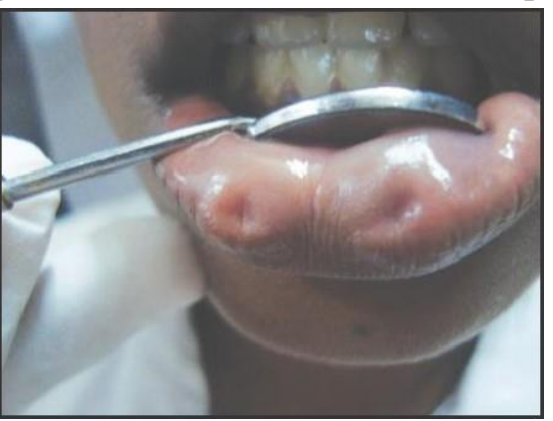

Fig 2:Eversion of the lower lip revealing the extent of the pit

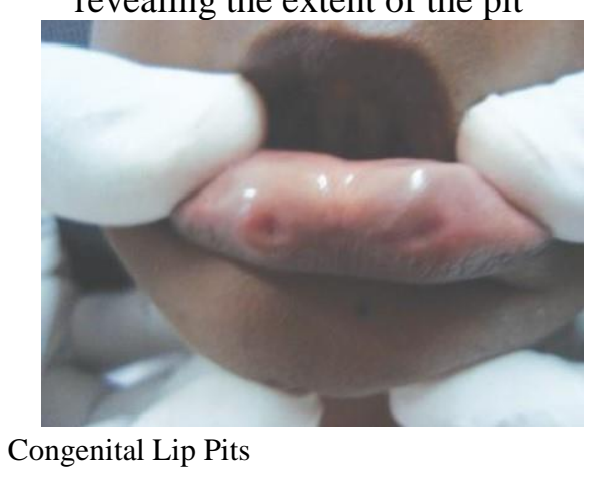

31 Journal of Scientific Dentistry, 1 (1), 2011 
1845 by DeMurquay. ${ }^{21}$ Lip pits are developmental anomalies that occur either as an isolated defect or in association with other developmental disturbances.

such as Popliteal Pterygium syndrome ${ }^{4}$, Van der Woude's syndrome Oral-facial-digital syndrome and Marres and Cremer's syndrome. ${ }^{161}$ It is often inherited as an autosomal dominant trait with variable penetrance. $\left[7,{ }^{8} 1\right.$

Lip pits may develop at the commissures of the lips or in the midline of which the former is much more common. The latter, usually bilateral and symmetric midline depressions develop on the vermilion border ofthe lower lip. These depressions represent fistulae lined by stratified squamous epithelium that traverse the underlying muscles for 5-25 $\mathrm{mm}$ and communicate with minor salivary glands through their excretory ducts. Viscous saliva can be expressed from the sinuses with pressure.

In normal development, fusion of the mandibular arch and sulcus lateralis of lower lip occurs at 5.5 weeks, whereas fusion of the maxillary and nasofrontal process occurs at 6 weeks. $\left.{ }^{9}\right]$ It is theorized that a common event may simultaneously disrupt fusion in both locations. This accounts for the strong association between lip pits and cleft lip and or palate. [10]

Parents often mistake these pits as depres sions caused by the maxillary central incisors, even though the pits are present from birth, months before maxillary incisors erupt. As often occurs, the depressions in our patient were thought to have developed because of pressure from his teeth and our patient had not had any other evaluation of the pits. Thus, it is important to have patients evaluated for other anomalies associated with the lip pits because the pits often are not recognized by the patient's primary care physician.

Lip pits may be left alone as in our case or surgically excised ifrepeated infections become problematic or for cosmetic reasons. [3,111 In excising the pits, it is important to ensure proper remov al ofthe entire tract because ofthe presence of salivary tissue in any residual tract will lead to cyst formation. The diameter of the tracts can vary between very small orifices or be as wide as $6 \mathrm{~mm}$.

Because the tracts can bifurcate, using a lacrimal probe to trace the tract may lead to leaving tract branches behind.

Prathima et al

\section{CONCLUSION}

The recognition of lip pits is important gi ven the multiple other associated anomalies. Proper evaluation and treatment of these associated abnormalities and genetic counseling is ofutmost importance. The treatment ofthis anomaly is either to leave it alone or surgical excision. Genetic evaluation to detect the genetic mutation is diagnostic and will assist in counseling.

\section{REFERENCES}

1. B rauen RO. General aspects of the bilateral cleft lip repair. In: Grabb WC, Rosenstein SW, Bzoch KR. Cleft lip and palate, 1st ed. Boston: Little/Brown;1971 P. 2789.

2. DeMarquay JN. Familial lip pit. Gaz. Med. (P aris);

1845:P.13:52.

3. Eisen D, Lynch DP. Developmental disorders. In: Eisen D and Lynch DP. The Mouth: diagnosis and treatment, I st ed. St Louis Mosby;1998:P.52

Herol$$
3 .
$$

, Samuel G, Baruchin AM. Popiteal pterygium syndrome. Clin Orthop 1986;209:194.

5. Schinezel A, Klausler M. The Van der Woude's

Syndrome (dominantly inherited lip pits and clefts). J Med Genet1 986:23.

6. Marres HA, Gremers CW, Congenita conductive or mixed deafness, preauricular sinus, external ear anomaly and commissural lip pits: An autosomal domi nant inherited syndrome. Ann Otolrhinollaryngol. 1991; 100:928.

7. Shprintzen RJ, Goldberg RB- The penetrance and variable expression of the Van der Woude's synd.

Implications for genetic counsel ing. Cleft palate J. 1980; 17:52.

8. Zarandi M, Givehchi G. Familial occurrence of lip pits: a case report. Acta Medica Iranica. 2002;40(2):132 5

9. Rizos M, Spyropoulos MN. Van der Woude syndrome: 
a review. Cardinal signs, Epidemiology, associated features, differential diagnosis, expressivity, genetic

Counseling and treatment. Eur J Orthod 26(1):1724.

10. Gorlin RJ, Coken MM, Levin LS. Syndromes of the Head Neck. 3rd ed. New York: Oxford University
Press; 1990:392-9.

1 1. Ziai, Mandana N, Benson, Aaron G Djalilian, Hamid

R. Congen ital Lip Pits and Van der Woude Syndrome. J

Cranio surg: $2005 ; 16(5): 93$

Congenital Lip Pits

Address for correspondence:

Dr. Prathima GS,

Consultant Pediatric Dentist

Suraksha Dental Specialities

Opp Bda Complex, Bsk -2stage

Bangalore: 560070

Email: dinoprat@yahoo.co.in

How to cite this article:

Prathima GS, Jayaraj D. Congenital Lower Paramedian Lip Pits - A Rare Case Report. Journal of Scientific Dentistry 2011;1(1):31-33

Source of Support: Nil, Conflict ofInterest: None declared 
33 Journal of Scientific Dentistry, 1(1), 2011 